\title{
Explaining the interactions between metaldehyde and acidic surface groups of activated carbon under different $\mathrm{pH}$ conditions
}

Anthuan Ferino-Pérez ${ }^{1}$, Juan José Gamboa-Carballo ${ }^{1}$, Zhuojun Li $^{2}$, Luiza C. Campos ${ }^{2, *}$, Ulises Jáuregui-Haza ${ }^{1,3, *}$

${ }^{1}$ Instituto Superior de Tecnologías y Ciencias Aplicadas (InSTEC), Universidad de La Habana, La Habana, CP 10600, Cuba, ulises.jauregui@infomed.sld.cu

${ }^{2}$ Department of Civil, Environmental and Geomatic Engineering, University College London, Gower Street, London WC1E 6BT, UK

${ }^{3}$ Instituto Tecnológico de Santo Domingo (INTEC), Área de Ciencias Básicas y Ambientales, Ave. de los Próceres, Santo Domingo, República Dominicana

*Corresponding authors: ulises.jauregui@infomed.sld.cu, ulises.jauregui@intec.edu.do, 1.campos@ucl.ac.uk

\section{Abstract}

Metaldehyde (MA) is an organic compound widely used in agriculture all around the world as molluscicide. There are growing concerns that relatively high levels of MA have been detected in surface water, which could be ascribed to the fact that it is transparent to common wastewater treatment processes. A theoretical study of the influence of activated carbon (AC) surface groups (SGs) on MA adsorption is done in order to help to understand the process and to evaluate the influence of the acid SGs over the adsorption in AC filters. Multiple Minima Hypersurface methodology was employed in order to study the interactions of the MA with acid SGs (hydroxyl and carboxyl) at acidic and neutral $\mathrm{pH}$, and at different hydration conditions explicitly taking into account the solvent influence. Selected structures were re-optimized using Density Functional Theory and posteriorly refined to achieve a well-defined electron density to characterize the interactions by the Quantum Theory of Atoms in Molecules approach. The obtained results showed that the presence of SGs enhances the adsorption process. The deprotonated carboxyl and hydroxyl SGs of AC models show the strongest interactions, suggesting greater adsorption at neutral $\mathrm{pH}$ which is in concordance with experimental data. The main interactions are of a dispersive nature between the pesticide and the $\pi$-cloud of the AC and hydrogen bonds between the MA and the acid SGs suggesting that the adsorption process is driven by a physisorption mechanism. Water acts as an intermediary between the AC and MA and competing with it for the adsorption sites.

Keywords: metaldehyde; activated carbon; acidic surface group; MMH; DFT; QTAIM 
Ferino-Pérez, A.; Gamboa-Carballo; J.J., Li, Z., Campos L.C.; Jáuregui-Haza U. (2019) Explaining the interactions between metaldehyde and acidic surface groups of activated carbon under different pH conditions. J Mol Graph Model., 90:94-103.

\section{Introduction}

Pesticides are considered as pollutants which endanger our limited water resources, and their widespread use has raised concerns due to their release and persistence in water bodies. Metaldehyde $\left(\mathrm{C}_{8} \mathrm{H}_{16} \mathrm{O}_{4}\right.$, CAS 108-62-3) is a cyclic tetramer of acetaldehyde $\left(\mathrm{CH}_{3} \mathrm{CHO}\right)$ with a molecular mass of $176.2 \mathrm{~g} \cdot \mathrm{mol}^{-1}$. Metaldehyde (MA) is a widely used selective pesticide in the UK, which is applied for agricultural purposes, gardening and used for targeting slugs. Globally, MA is the active ingredient in $80 \%$ of slug pellets [1]. It is considered to be an extremely polar organic compound with a relatively low $\log$ octanol/water partition coefficient $\left(\mathrm{K}_{\mathrm{ow}}\right)$ of 0.12 , which suggests low sorption potential [1,2]. As a result of extensive use of MA, it is reported by the UK Environment Agency that MA has been detected in surface water with a concentration up to $8 \mu \mathrm{g} / \mathrm{L}$ [3]. Furthermore, MA has also been found in treated drinking water in the UK at, up to $1 \mu \mathrm{g} / \mathrm{L}$; this exceeds the EU and UK national standard of $0.1 \mu \mathrm{g} / \mathrm{L}$ [4]. Therefore, this implies that modern remediation techniques are not suitable for the removal of this pesticide from water bodies to an adequate extent. It is therefore of great significance to study and acquire a better understanding of MA for it to be removed from the water. Figure 1a shows a representation of this pesticide.

Adsorption by activated carbon (AC) is one of the most common treatment methods to remove organic pollutants such as dyes $[5,6]$, industrial chemicals $[7,8]$ and pesticides $[9,10]$. The low cost, high efficiency, simplicity and ease in the up-scaling of adsorption processes using these porous materials makes the adsorption technique attractive for the removal of organic pollutants [11]. However, it has been reported that granular activated carbon (GAC) as a type of AC is not effective to remove metaldehyde from water [4]. Therefore, in order to select the best-suited AC for metaldehyde remotion, it is significant to study the adsorption mechanisms of MA onto AC. It is important to notice that this investigation is centered in the surface oxygen complexes (hydroxyl and carboxyl groups specifically) as they are responsible for many physic-chemical and surface properties of carbons [12]. Previous investigations about the influence of -COOH and -OH surface groups seem to agree with the fact that dispersive interactions with the $\pi$-cloud of the activated carbon play a leading role in the adsorption process, giving place, principally, to a physisorption of the substrate of interest onto the AC surface [13-15]. It is worth mentioning that these cited works only studied the protonated form of these surface groups neglecting the $\mathrm{pH}$ influence on these chemical species.

The application of computational chemistry methods allow an economization of the material resources while optimizing the work and security of the researchers and technicians [16]. The influence of surface groups (SG) content over adsorption properties has been reported and studied to some extent theoretically for porous carbons (mainly AC and soot particles) [9, 17-23] in the last few years employing different AC models. In 2014 Enriquez-Victorero et. al [20] using Multiple Minima Hypersurface (MMH) [24, 25] and Density Functional Theory [26, 27] studied 
Ferino-Pérez, A.; Gamboa-Carballo; J.J., Li, Z., Campos L.C.; Jáuregui-Haza U. (2019) Explaining the interactions between metaldehyde and acidic surface groups of activated carbon under different pH conditions. J Mol Graph Model., 90:94-103.

the interactions of $\gamma$ and $\beta$-hexachlorocyclohexane with an AC model based on a naphthalene molecule, obtaining results that allow for explaining the adsorption process at different $\mathrm{pH}$ conditions. Subsequently, Hernández-Valdés et. al [21] applied this approach to evaluate the interactions of paracetamol and its iodine-labeled analogous (I-paracetamol) with AC, improving the AC model to a coronene sheet. The results obtained in this work shows that I-paracetamol does not adsorb into AC in the same extension, a fact that was experimentally proved. More recently, Gamboa-Carballo et. al [22], while studying adsorption of chlordecone into AC, established a work flow that incorporated Quantum Theory of Atoms in Molecules [28, 29] to the methods used by Hernández-Valdés et al. [21] for quantitatively describing the interactions presents in the studied systems. This strategy was later used by Melchor et al. [23] for describing the interactions at a basic $\mathrm{pH}$ of hydrated chlordecone with an $\mathrm{AC}$, which, when coupled with the results by Gamboa-Carballo et. al [22] allows the characterization of the absorption of this pollutant in a wide $\mathrm{pH}$ range, and to match the theoretical calculations with experimental adsorption isotherms. Therefore, this strategy is the one used in our work aiming to investigate, for the first time, the influence of activated carbon surface groups on metaldehyde adsorption onto $\mathrm{AC}$, in order to improve the selection process of the best-suited ACs according to its SGs composition.

\section{Materials and Methods}

\subsection{System under study}

Models that correctly describe ACs' morphology, topology and constitution usually do so at a high computational cost. Therefore, the use of small polycycles such as naphthalene [9, 20, 30], coronene [21, 22, 31-34], and their oxidized derivatives is very popular for theoretical studies that aim to characterize their interactions with variety of molecules. The use of such small models saves computational resources, and allows either an application of a relatively high level of calculations or a thorough exploration of the interactions present in the system under study [22].

a

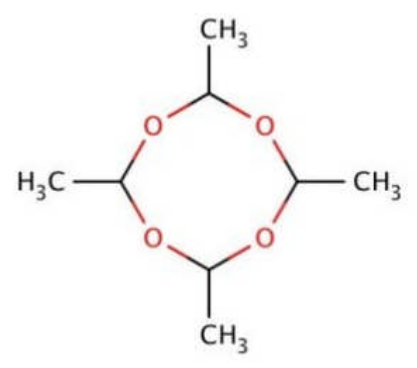

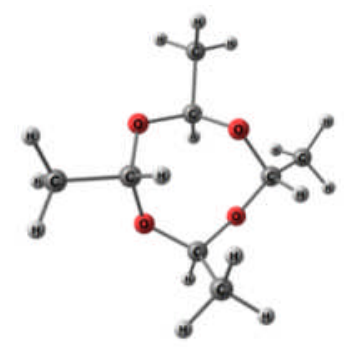

$\mathbf{b}$
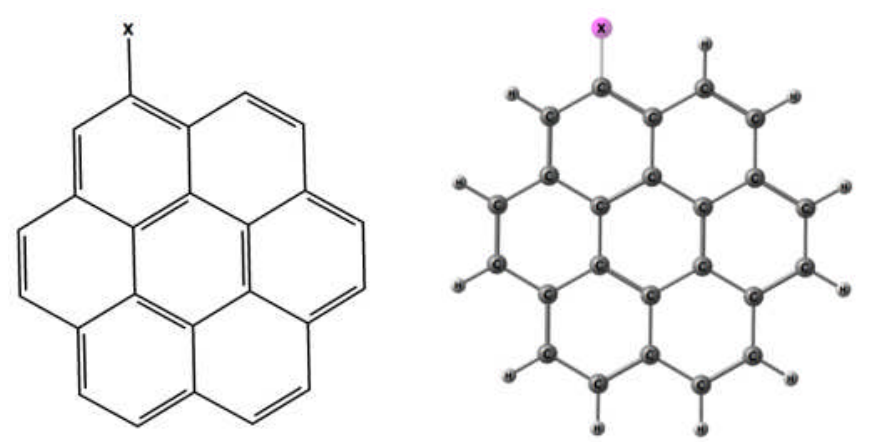

Figure 1. Metaldehyde (a) and activated carbon model (b) of coronene (X=H) and its oxidized forms $\left(\mathrm{X}=\mathrm{COOH}, \mathrm{COO}^{-}, \mathrm{OH}^{-} \mathrm{O}^{-}\right)$. 
Ferino-Pérez, A.; Gamboa-Carballo; J.J., Li, Z., Campos L.C.; Jáuregui-Haza U. (2019) Explaining the interactions between metaldehyde and acidic surface groups of activated carbon under different pH conditions. J Mol Graph Model., 90:94-103.

Hence, a model of AC made up of a seven-membered ring graphene sheet (coronene) with and without an acidic functional group on the edge (Figure 1b) was selected to study the effect of hydroxyl and carboxyl groups during adsorption. This model neglects the influence of pore shape, defects, pore size and pore connectivity, but instead allows the performance of a large number of calculations with a higher theoretical level, in order to achieve a better chemical description of the studied phenomena. Although, it has been studied that hydroxyl groups may be located in the basal plane of the carbonaceous surface [35], and could play an important role in the adsorption process, the selected model $[22,23]$ in this study only considers modifications in the edge of coronene that do not affect the aromaticity of the system. Depicted in Figure 1b, the models provide both the aromatic character (or graphene structure) and the SGs at the edges of AC. Twenty systems of the "complexes" $\mathrm{MA} / \mathrm{AC} /\left(\mathrm{H}_{2} \mathrm{O}\right)_{\mathrm{n}=0-3}$ were selected in order to describe the influence of the surface groups in the adsorption process. The water molecules were included to take into account the influence of the solvent in this process. It is worth mentioning that the $\mathrm{pH}$ influence was take into account implicitly, deprotonating the acidic surface groups (SGs) in the AC model.

\subsection{Multiple Minima Hypersurfaces (MMH) calculations}

A study of the interaction space for MA/AC-SGs/( $\left.\mathrm{H}_{2} \mathrm{O}\right)_{\mathrm{n}=0-3}$ was carried out by the methodology of Multiple Minima Hypersurfaces (MMH) [24, 25]. For each of the 20 studied systems, 700 random configurations were generated and optimized.

The MMH methodology usually hinges on semiempirical methods [20-25, 36-38] for the evaluation of the energies, while using statistical mechanics to obtain thermodynamic properties related to the molecular association. The main procedure of this approach constructs several random non-redundant molecular geometries, starting from the independently optimized structures of metaldehyde, activated carbon (AC) and water. Thermodynamic properties such as association energy $\left(\Delta \mathrm{E}_{\mathrm{ASSOC}}\right)$, association entropy $\left(\Delta \mathrm{S}_{\mathrm{ASSOC}}\right)$, and Helmholtz free energy $\left(\triangle \mathrm{A}_{\mathrm{ASSOC}}\right)$, are then calculated by this procedure. The term association energy represents the thermodynamic association energy calculated through the statistically weighted sum (i.e. partition function) of the representative "supermolecule" states, it will be called "mean association energy" $\left(\Delta \mathrm{E}_{\mathrm{ASSOC}}\right)$ from now [25]. A Boltzmann distribution is used to calculate the thermally averaged state of the typical macroscopic system at room temperature (298.15 K). Although, the Gibbs's free energy of association $\left(\Delta \mathrm{G}_{\text {assoc }}\right)$ is the thermodynamic criteria used to define the spontaneity of a process, the association energy $\left(\Delta \mathrm{E}_{\mathrm{assoc}}\right)$ was used in this study. This criterion has been profusely used in the past [20-25, 36-38], since it is computationally simpler compared to $\Delta \mathrm{G}_{\text {assoc }}$, and it avoids having to calculate the association entropies. The $\Delta \mathrm{E}_{\text {assoc }}$ is defined as $\Delta \mathrm{E}_{\text {assoc }}=$ $E_{\text {supermolecule }}-E_{\text {reference }}$ where, $E_{\text {supermolecule }}$ is the energy of the molecular complex formed by the AC model (with and without SGs under study) and the interacting molecules (MA and water) calculated in the geometry of the formed complex. $E_{\text {reference }}$ comprises the sum of the 
Ferino-Pérez, A.; Gamboa-Carballo; J.J., Li, Z., Campos L.C.; Jáuregui-Haza U. (2019) Explaining the interactions between metaldehyde and acidic surface groups of activated carbon under different pH conditions. J Mol Graph Model., 90:94-103.

energies of each independent molecule calculated in their isolated geometries. A favorable thermodynamic association implies that the supermolecule will be more stable than the isolated molecules, namely a greater absolute value of $\Delta \mathrm{E}_{\text {assoc }}$ will correspond to more energetically favorable associations [22].

For the generation of the 700 random configurations the GranadaR2 [39] program was chosen to enable a rational use of the computational resources, and a better analysis when the interaction space was explored. This program is a modification of GRANADA [40] software that placed the solute in the center of a cubic box surrounded by solvent molecules. The employment of GranadaR2 allows the optimization of the search space restricting the area for the generation of structures to the region of interest for the study in question. This functionality can be used to make a more rational use of computational resources. It is also very useful to improve analysis when exploring the configurational space involving an elongated shape solute [21, 39], as in our case.

The semiempirical Hamiltonian PM7 [41] was used for the optimization of the 700 geometries, using the software MOPAC2016 [42]. PM7 is a semiempirical Hamiltonian that improves the description of the $\mathrm{H}$-bond and dispersive interactions with respect to the previous semiempirical methods, except for PM6-D3H4X. Despite the fact that the PM6-D3H4X method gives the best results, PM7 yields only slightly inferior results, and brings additional improvements in the description of other molecular properties. Therefore, PM7 can be recommended as the most robust semiempirical quantum mechanical method [43].

\subsection{Re-optimization of distinctive structures}

After the MMH calculations, the representative structures of the systems MA/AC-SGs/ $\left(\mathrm{H}_{2} \mathrm{O}\right)_{\mathrm{n}=0 \text { - }}$ 3 were re-optimized using Density Functional Theory (DFT) [26, 27]. All calculations were performed using the software package Gaussian09 [44]. For this re-optimization, a hybrid functional that uses the meta-generalized gradient approximation: M06-2X [31, 45] was employed (along with the $6-311++\mathrm{G}(\mathrm{d}, \mathrm{p})$ basis). It has been reported that this combination correctly describes the interactions found in non-covalent bonded dimers [45], particularly in the case of van der Waals interactions presented in this studied system. The solvent effects were considered with up to three water molecules introduced in the system, as previously stated.

\subsection{Topologic analysis of the electron density}

To obtain a better description of the interactions in the studied systems, the electron density was re-optimized using the Pople basis $6-311++\mathrm{G}(2 \mathrm{df}, 2 \mathrm{pd})$. The representative structure of the MA/AC-SGs/ $\left(\mathrm{H}_{2} \mathrm{O}\right)_{\mathrm{n}=0-3}$ complexes was studied using Quantum Theory of Atoms in Molecules (QTAIM) as proposed by Bader et al. [28, 29]. QTAIM helps analyze the nature of the interactions based on Nakanishi's criteria $[46,47]$, which is one of the main goals of this investigation. The typical ranges of these criteria are shown in Tables $\mathbf{S 1}$ and $\mathbf{S 2}$ of the Supporting Information. This analysis was made using the Multiwfn 3.3.6 software package [48]. 
Ferino-Pérez, A.; Gamboa-Carballo; J.J., Li, Z., Campos L.C.; Jáuregui-Haza U. (2019) Explaining the interactions between metaldehyde and acidic surface groups of activated carbon under different pH conditions. J Mol Graph Model., 90:94-103.

\section{Results and discussion}

\subsection{MMH calculations}

A study was carried out to determine the spatial configurations that correspond to the interactions between the metaldehyde and the acidic carboxyl $(-\mathrm{COOH})$, and the hydroxyl $(-\mathrm{OH})$ surface groups, at neutral and acidic $\mathrm{pH}$ values. In each of the 20 studied systems, 700 random configurations were generated and optimized. The influence of $\mathrm{pH}$ was taken into account by deprotonating the surface groups to analyze the corresponding $\mathrm{pH}$ range, $\mathrm{pH}>5$ when the carboxyl group is deprotonated and $\mathrm{pH}>8$ when it is the hydroxyl group. As MA does not have labile hydrogen atoms present in its structure, it is not affected by $\mathrm{pH}$ changes; therefore, the studies at neutral $\mathrm{pH}$ could be extensive for basic conditions. Furthermore, the role of solvent in the sorption process was studied by including 1 to 3 water molecules, and assuming that these were the number of solvent molecules presented in the first solvation sphere [20]. Figure 2 shows the mean association energies at $298 \mathrm{~K}$ for the systems described before, and Table $\mathbf{S 3}$ displays the results obtained by this methodology for the studied systems.

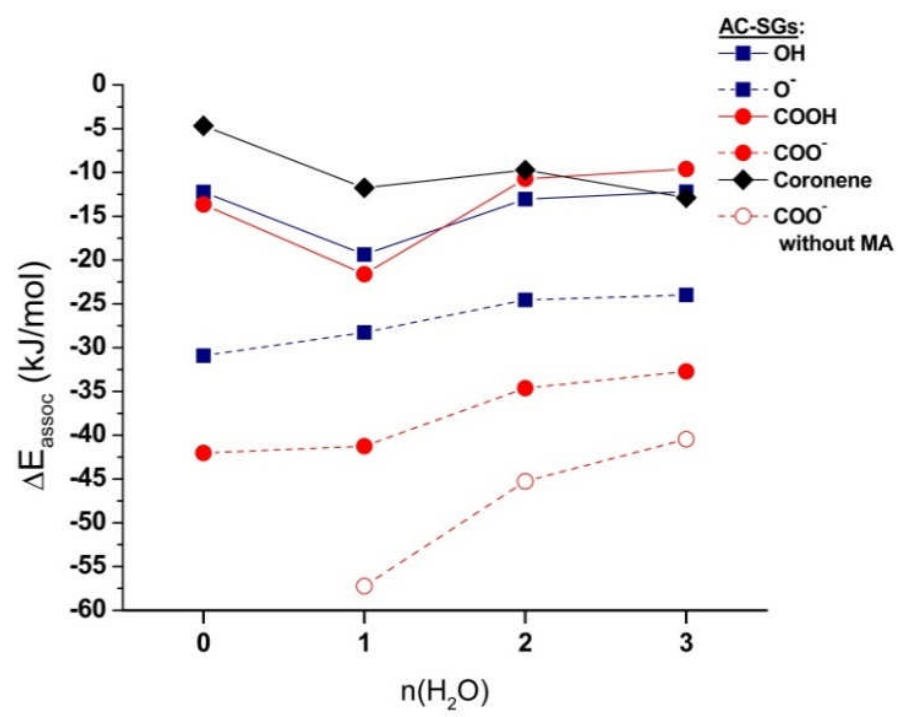

Figure 2. Mean association energies of metaldehyde interaction with coronene and the SGs of activated carbon at acidic $(\mathrm{COOH}$ and $\mathrm{OH})$ and neutral $\left(\mathrm{COO}^{-}\right.$and $\left.\mathrm{O}^{-}\right) \mathrm{pH}$ values. The graph " $\mathrm{COO}^{-}$ without MA" represents the interactions of this SG of activated carbon only with water molecules [22].

Comparing the association energies obtained for MA and different SGs with those calculated by Gamboa-Carballo et al. [22] for SGs with only water molecules at the same level of theory (PM7), it is evident that interactions with water molecules are favored over the interactions with MA, from a thermodynamic point of view. In Figure 2, energies for the interactions with water molecules of the - $\mathrm{COO}^{-}$group were reported as an example of this statement which implies that water competes with MA for adsorption sites. This result is in agreement with the experimental observations reported by Busquets et al. [49]. Furthermore, it was observed that water molecules usually act as intermediaries between MA and activated carbon. Figure 3-5 (top) shows the global 
Ferino-Pérez, A.; Gamboa-Carballo; J.J., Li, Z., Campos L.C.; Jáuregui-Haza U. (2019) Explaining the interactions between metaldehyde and acidic surface groups of activated carbon under different pH conditions. J Mol Graph Model., 90:94-103.

minima obtained through the $\mathrm{MMH}$ methodology. Values of $\Delta \mathrm{E}_{\mathrm{assoc}}$ and direct interaction of the pollutant with SGs decreased while the number of water molecules increased, thisindicates competitive adsorption and the formation of the first solvation sphere.

On the other hand, comparing the association energies when coronene was used as an adsorbent with the ones when the surface groups were introduced to the activated carbon structure, it seems that the introduction of the later enhance the sorption of MA. However, for the acidic groups at neutral $\mathrm{pH}(-\mathrm{COOH}$ and $-\mathrm{OH})$ the differences in the energies were not considerable overall in the case where three water molecules were present.

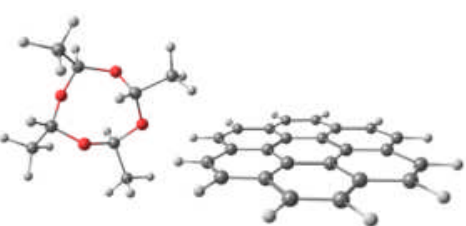

MA/Coronene.1

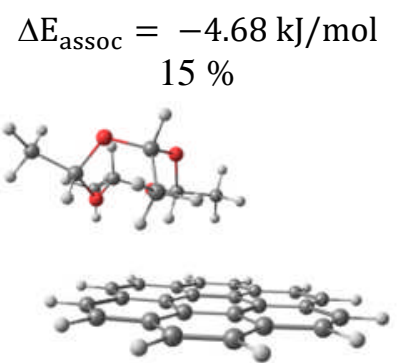

MA/Coronene. $1 *$

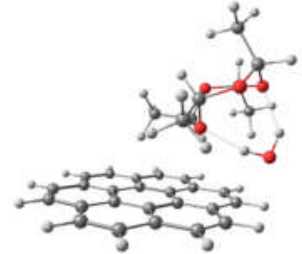

MA/Coronene/ $\mathrm{H}_{2} \mathrm{O} .1$

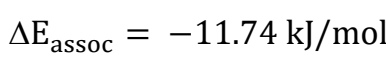

$16 \%$

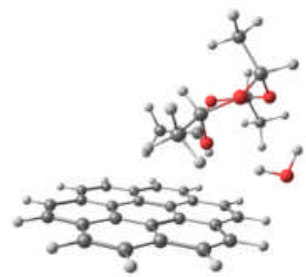

MA/Coronene/ $\mathrm{H}_{2} \mathrm{O} .1^{*}$

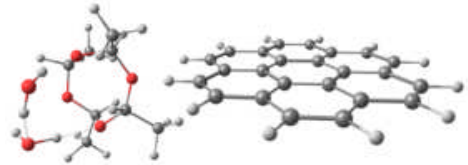

MA/Coronene $/\left(\mathrm{H}_{2} \mathrm{O}\right)_{2} .1$

$\Delta \mathrm{E}_{\text {assoc }}=-9.72 \mathrm{~kJ} / \mathrm{mol}$

$17 \%$

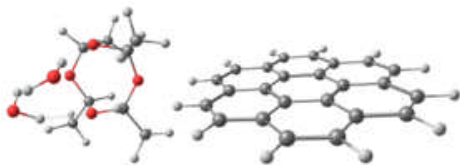

MA/Coronene/ $\left(\mathrm{H}_{2} \mathrm{O}\right)_{2} .1 *$

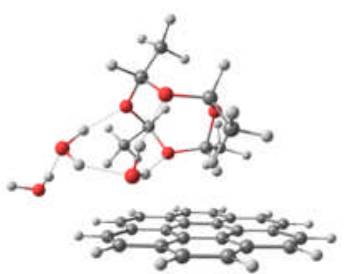

MA/Coronene/ $\left(\mathrm{H}_{2} \mathrm{O}\right)_{3} .1$

$\Delta \mathrm{E}_{\text {assoc }}=-12.88 \mathrm{~kJ} / \mathrm{mol}$ $20 \%$

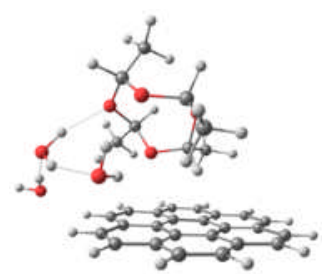

MA/Coronene/( $\left.\mathrm{H}_{2} \mathrm{O}\right)_{3} .1^{*}$

Figure 3. Distinctive minima structures and their $\mathrm{MMH}$ energies and populations (\%) for the systems MA/Coronene/ $\left(\mathrm{H}_{2} \mathrm{O}\right)_{\mathrm{n}=0-3}$. Numbers denote structures found at PM7, while quoted numbers account for the corresponding re-optimized structures at M06-2X/6-31++G(d,p) level of theory.

Additionally, Figure 2 demonstrates that the interactions are energetically favored with the charged hydroxylic and carboxylic surface groups; which indicates that the sorption will be more favorable at the $\mathrm{pH}$ intervals where the surface groups are deprotonated $\mathrm{pH}>5$ for the carboxyl group and $\mathrm{pH}>8$ for the hydroxyl group). It is noted that the carboxyl group presents a more thermodynamically favorable adsorption process; this result agrees with the experimental approach by Busquets et al. [49] and Salvestrini et al. [10].

Despite the fact that the interactions at acidic $\mathrm{pH}$ (with the groups $-\mathrm{OH}$ and $-\mathrm{COOH}$ ) are less favored than the ones with charged surface groups (Figure 1), it can be seen that in both cases the introduction of a water molecule stabilized the system due to the establishment of a system of hydrogen bonds. Here water acts as an intermediary between the hydrogen atom of the surface group of AC and the two oxygen atoms of MA (Figure 4). The presence of the acidic hydrogen seems to be essential for the formation of this set of H-bonds, hence, the stabilization of the complex cannot be found in the case of deprotonated groups. 
Ferino-Pérez, A.; Gamboa-Carballo; J.J., Li, Z., Campos L.C.; Jáuregui-Haza U. (2019) Explaining the interactions between metaldehyde and acidic surface groups of activated carbon under different pH conditions. J Mol Graph Model., 90:94-103.

Analysis of the structures (Figures 3-5) and the results obtained by the MMH/PM7 calculations suggest that in addition to the formation of the hydrogen bonds, the dispersive interactions between the MA and the $\pi$-cloud of the activated carbon might be the main driving forces of the adsorption process of MA onto AC from aqueous solution.

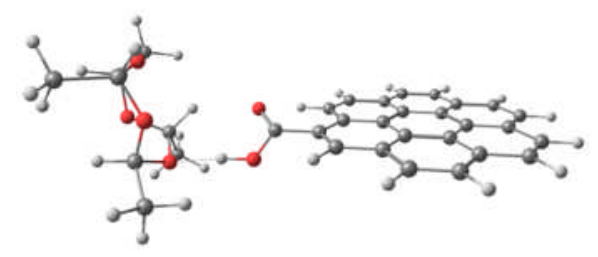

MA/AC-COOH.1

$\Delta \mathrm{E}_{\text {assoc }}=\underset{51 \%}{-13.65 \mathrm{~kJ} / \mathrm{mol}}$

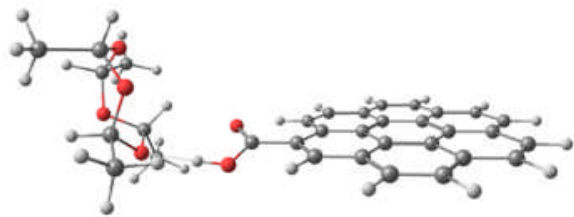

MA/AC-COOH. $1^{*}$

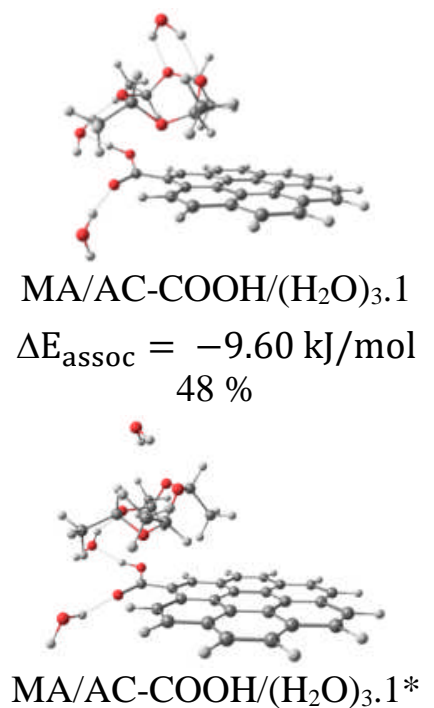

$\mathrm{MA} / \mathrm{AC}-\mathrm{COOH} /\left(\mathrm{H}_{2} \mathrm{O}\right)_{3.1} \cdot{ }^{*}$

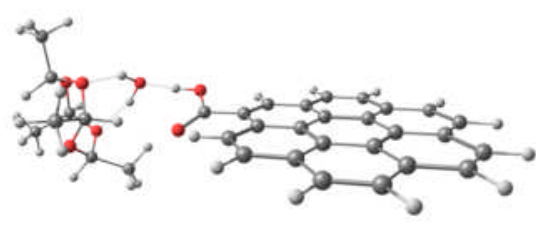

$\mathrm{MA} / \mathrm{AC}-\mathrm{COOH} / \mathrm{H}_{2} \mathrm{O} .1$

$$
\Delta \mathrm{E}_{\text {assoc }}=\frac{-21.60 \mathrm{~kJ} / \mathrm{mol}}{78 \%}
$$

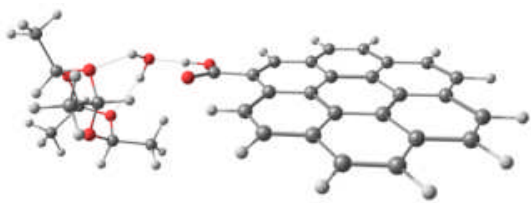

$\mathrm{MA} / \mathrm{AC}-\mathrm{COOH} / \mathrm{H}_{2} \mathrm{O} .1 *$

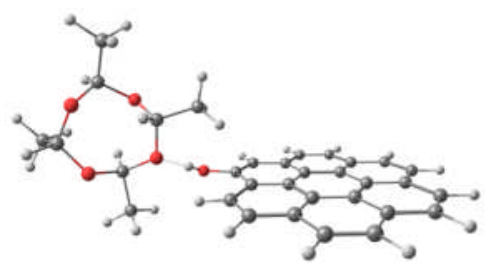

MA/AC-OH.1

$\Delta \mathrm{E}_{\text {assoc }}=-12.22 \mathrm{~kJ} / \mathrm{mol}$

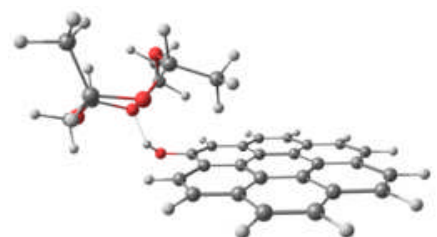

$\mathrm{MA} / \mathrm{AC}-\mathrm{OH} .1^{*}$
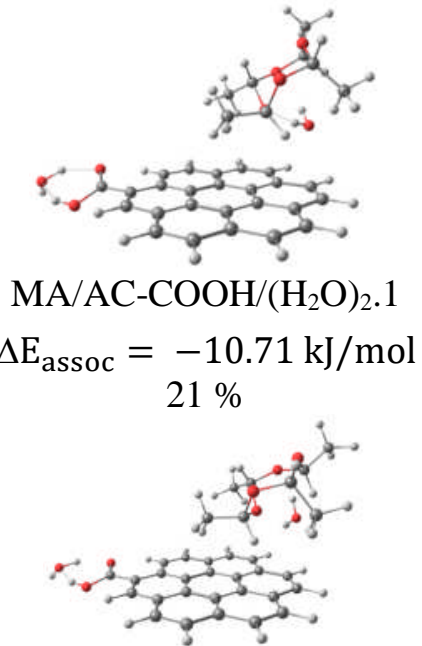

$\mathrm{MA} / \mathrm{AC}-\mathrm{COOH} /\left(\mathrm{H}_{2} \mathrm{O}\right)_{2 .} .1$ *

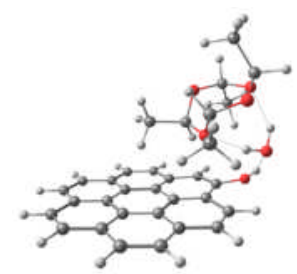

$\mathrm{MA} / \mathrm{AC}-\mathrm{OH} / \mathrm{H}_{2} \mathrm{O} .1$

$\Delta \mathrm{E}_{\text {assoc }}=-19.36 \mathrm{~kJ} / \mathrm{mol}$ $60 \%$

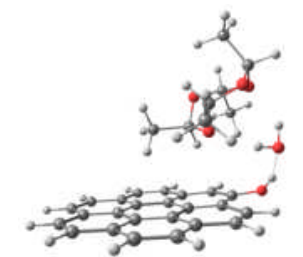

$\mathrm{MA} / \mathrm{AC}-\mathrm{OH} / \mathrm{H}_{2} \mathrm{O} .1$ *
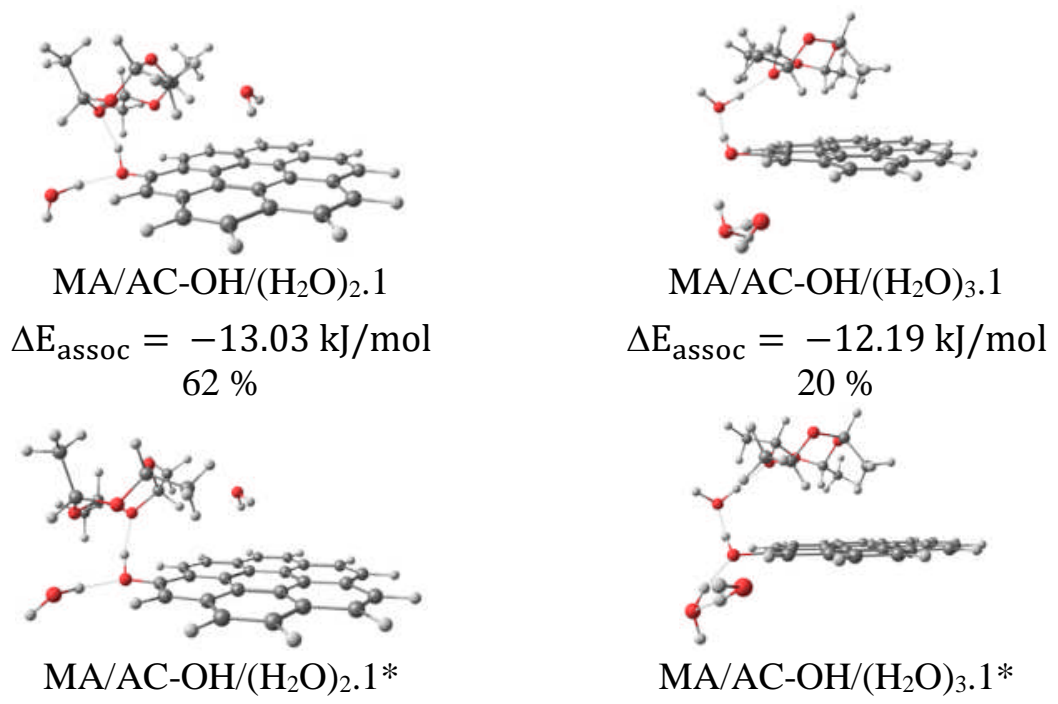
Ferino-Pérez, A.; Gamboa-Carballo; J.J., Li, Z., Campos L.C.; Jáuregui-Haza U. (2019) Explaining the interactions between metaldehyde and acidic surface groups of activated carbon under different pH conditions. J Mol Graph Model., 90:94-103.

Figure 4. Distinctive minima structures and their $\mathrm{MMH}$ populations (\%) and energies for the systems MA/AC-SGs $/\left(\mathrm{H}_{2} \mathrm{O}\right)_{\mathrm{n}=0-3}$ with uncharged surface groups $(\mathrm{pH}<5)$. Numbers denote structures found at PM7, while quoted numbers account for the corresponding re-optimized structures at M06-2X/6-31++G(d,p) level of theory.

Finally, comparing the adsorption of the MA in AC to other pesticides such as hexachlorocyclohexane and chlordecone [20,22, 23] (used in other theoretical studies), it can be concluded that the amount of MA adsorbed should be much lower than other pesticides.

The global minima and additional structures of interest due to exhibited geometry found by the MMH study were selected for further refinement by DFT calculations. A total of 40 representative structures of the systems $\mathrm{MA} / \mathrm{AC} /\left(\mathrm{H}_{2} \mathrm{O}\right)_{\mathrm{n}=0,1,2,3}$ were chosen, always taking into account that according to MMH methodology they have a Boltzmann population greater than a $5 \%$.

\subsection{Refinement of the representative structures using DFT M06-2X}

The optimization of previously selected structures by MMH was carried out using DFT, with the objective of achieving a better characterization of the molecular geometry, the strength and the nature of the present interactions in the systems under study. The 40 selected complexes were optimized using the M06-2X/6-31++G(d,p) method. This re-optimization describes the significant structures on a more rigorous level of theory. The Basis Set Superposition Error (BSSE) was not calculated, as the comparison of systems' stability was performed using thermodynamic data calculated through the semi-empirical method used that did not include BSSE.

Figures 3-5 (bottom) show the obtained geometries for the structures of the global MMH minima after being re-optimized using DFT. Figures S1-S3 present the obtained geometries for the rest of the selected systems. The re-optimized geometries do not differ significantly from the ones obtained from the semi-empirical optimization. However, in several cases some changes occurred in the geometries of the supermolecules, increasing the interactions between MA and the $\pi$-cloud. This could be taken as a signal of the importance of this kind of interaction in the stabilization of the studied systems.

The main interactions, as suggested by interatomic distances, have a dispersive character accompanied by the formation of hydrogen bonds. It is important to point out that there is a great tendency for water to associate via these kinds of electrostatic interactions with the SGs, and therefore, competes with MA for adsorption sites. It was observed that water molecules usually act as intermediaries between MA and the activated carbon (Figure 3-5). The sorption was then enhanced by the increment in the stability of the formed complexes that caused interactions with the SGs. The presence of all these non-covalent interactions suggests that the adsorption process should go through a physisorption mechanism. 
Ferino-Pérez, A.; Gamboa-Carballo; J.J., Li, Z., Campos L.C.; Jáuregui-Haza U. (2019) Explaining the interactions between metaldehyde and acidic surface groups of activated carbon under different pH conditions. J Mol Graph Model., 90:94-103.

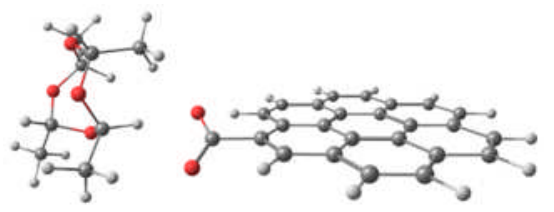

$\mathrm{MA} / \mathrm{AC}-\mathrm{COO}^{-} .1$

$\Delta \mathrm{E}_{\text {assoc }}=\frac{-42.02 \mathrm{~kJ} / \mathrm{mol}}{26 \%}$

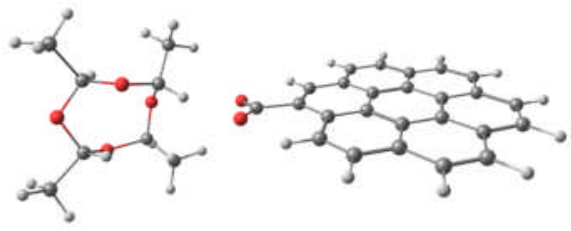

MA/AC-COO-. $1^{*}$

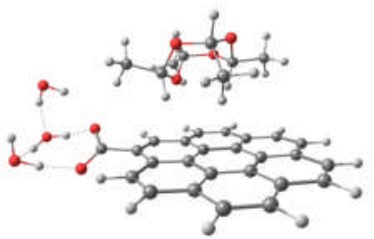

$\mathrm{MA} / \mathrm{AC}-\mathrm{COO} /\left(\mathrm{H}_{2} \mathrm{O}\right)_{3} .1$

$\Delta \mathrm{E}_{\text {assoc }}=-32.73 \mathrm{~kJ} / \mathrm{mol}$ $48 \%$

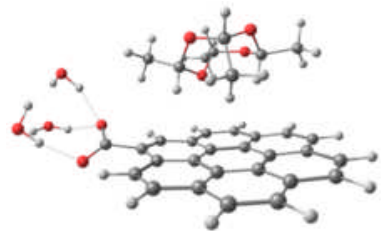

$\mathrm{MA} / \mathrm{AC}-\mathrm{COO}^{-} /\left(\mathrm{H}_{2} \mathrm{O}\right)_{3 .} .^{*}$

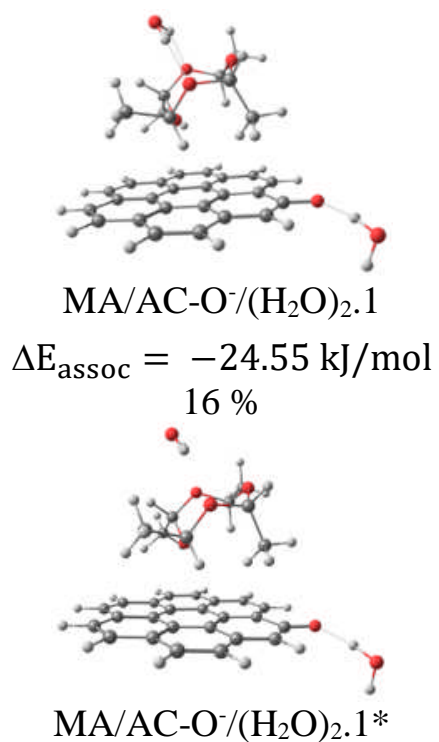

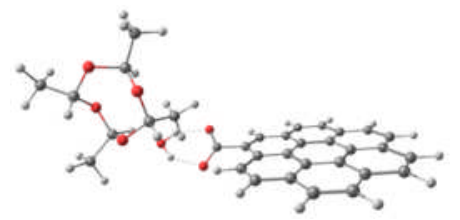

$\mathrm{MA} / \mathrm{AC}-\mathrm{COO}^{-} / \mathrm{H}_{2} \mathrm{O} .1$

$\Delta \mathrm{E}_{\mathrm{assoc}}=-41.25 \mathrm{~kJ} / \mathrm{mol}$ $41 \%$

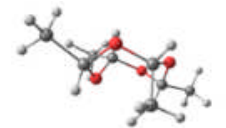

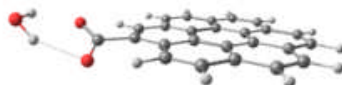

$\mathrm{MA} / \mathrm{AC}-\mathrm{COO} / \mathrm{H}_{2} \mathrm{O} .1 *$

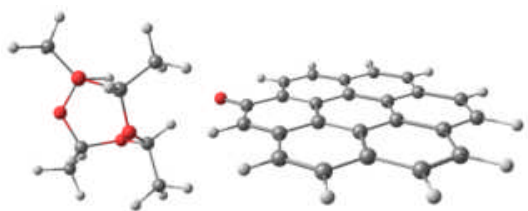

MA/AC-O -1

$\Delta \mathrm{E}_{\mathrm{assoc}}=-30.92 \mathrm{~kJ} / \mathrm{mol}$ $32 \%$

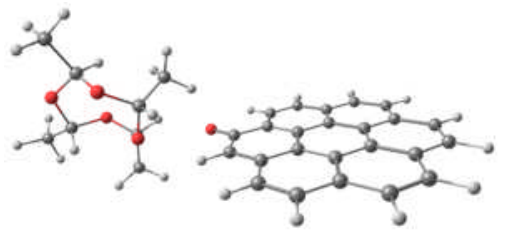

MA/AC-O $.1 *$

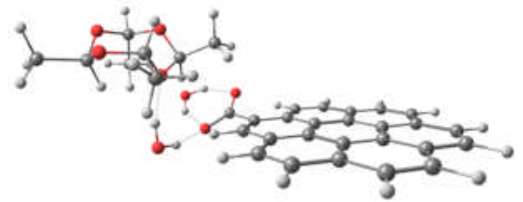

$\mathrm{MA} / \mathrm{AC}-\mathrm{COO}^{\circ} /\left(\mathrm{H}_{2} \mathrm{O}\right)_{2} .1$

$\Delta \mathrm{E}_{\text {assoc }}=-34.62 \mathrm{~kJ} / \mathrm{mol}$ $21 \%$

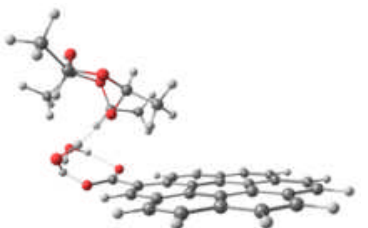

$\mathrm{MA} / \mathrm{AC}-\mathrm{COO}^{-} /\left(\mathrm{H}_{2} \mathrm{O}\right)_{2 .}$. $^{*}$

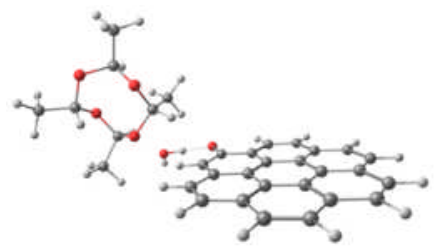

MA/AC-O $/ \mathrm{H}_{2} \mathrm{O} .1$

$\Delta \mathrm{E}_{\text {assoc }}=-28.26 \mathrm{~kJ} / \mathrm{mol}$ $48 \%$

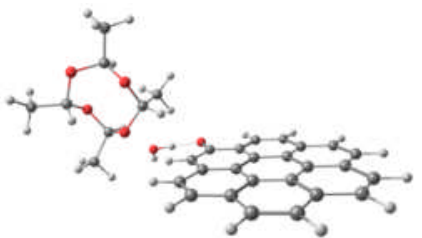

$\mathrm{MA} / \mathrm{AC}-\mathrm{O} / \mathrm{H}_{2} \mathrm{O} .1^{*}$

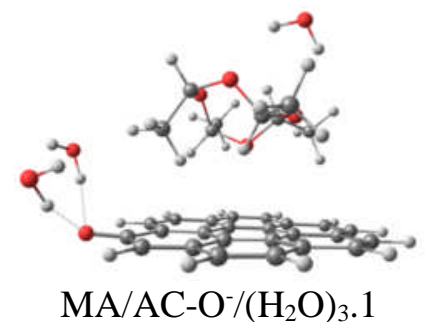

$\Delta \mathrm{E}_{\text {assoc }}=-23.98 \mathrm{~kJ} / \mathrm{mol}$

$29 \%$

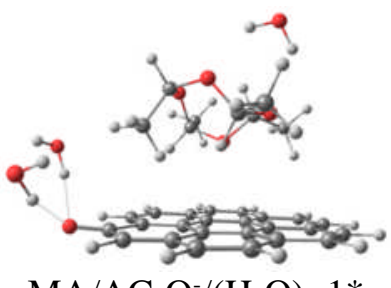

MA/AC-O $/\left(\mathrm{H}_{2} \mathrm{O}\right)_{3 .} 1^{*}$

Figure 5. Distinctive minima structures and their MMH populations (\%) and energies for the systems MA/AC$\mathrm{SGs} /\left(\mathrm{H}_{2} \mathrm{O}\right)_{\mathrm{n}=0-3}$ with charged surface groups $(\mathrm{pH}>8)$. Numbers denote structures found at PM7, while quoted numbers account for the corresponding re-optimized structures at M06-2X/6-31++G(d,p) level of theory.

\subsection{QTAIM analysis}

For a more rigorous characterization of the interactions in MA/AC-SGs/ $\left(\mathrm{H}_{2} \mathrm{O}\right)_{\mathrm{n}=0-3}$ a topologic analysis of the electronic density (QTAIM) was performed. The application of the QTAIM 
Ferino-Pérez, A.; Gamboa-Carballo; J.J., Li, Z., Campos L.C.; Jáuregui-Haza U. (2019) Explaining the interactions between metaldehyde and acidic surface groups of activated carbon under different pH conditions. J Mol Graph Model., 90:94-103.

analysis allows characterizing the topology of the electronic density $(\rho)$ and its Laplacian $\left(\nabla^{2} \rho\right)$ at the bond critical points (BCPs), and to describe the molecular interactions and classify them according to generally accepted criteria. In this work, Nakanishi's criteria [46, 47] were used for this purpose. Furthermore, other $\rho$ dependent functions such as the total energy density $\left(\mathrm{H}_{\mathrm{BCP}}\right)$, the potential-kinetic energy density ratio $\left(\mathrm{V}_{\mathrm{BCP}} / \mathrm{G}_{\mathrm{BCP}}\right)$, and the ellipticity of the electronic density (ع) were used. It is important to point out that the term "weak H-bond" was used in the classification of the interactions' types using Nakanishi's criteria when the evaluated interaction fulfilled several, but not all the parameters of a typical H-bond interaction. Table 1 presents the values of these properties at the BCPs for the distinctive interactions of the system MA/AC$\mathrm{OH} /\left(\mathrm{H}_{2} \mathrm{O}\right)_{3} .1 *$. Table $\mathbf{S} 4$ shows the characterization of the interactions for all the studied systems.

Table 1. Characterization of the distinctive interactions using Nakanishi's criteria for the complex MA/AC-OH/( $\left.\mathrm{H}_{2} \mathrm{O}\right)_{3} .1^{*}$

\begin{tabular}{|c|c|c|c|c|c|c|c|c|c|}
\hline Complex & Interactions & Atoms $^{\mathrm{a}}$ & 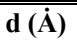 & $\rho_{\mathrm{BCP}}($ a.u. $)$ & $\nabla^{2} \rho_{\text {BCP }}$ (a.u.) & $\mathbf{H}_{\mathrm{BCP}}$ (a.u.) & $\mathbf{V}_{\mathrm{BCP}} / \mathbf{G}_{\mathrm{BCP}}$ & $\varepsilon$ & Type $^{\text {b }}$ \\
\hline \multirow[t]{12}{*}{ МА/AC-OH/( $\left./ \mathrm{H}_{2} \mathrm{O}\right)_{3} .1^{*}$} & 1 & "H...C (MA...AC) & 2.63 & 0.0096 & 0.032 & 0.00133 & -0.80 & 2.97 & vdW \\
\hline & 2 & H...C (MA...AC) & 2.89 & 0.0059 & 0.017 & 0.00072 & -0.80 & 1.70 & vdW \\
\hline & 3 & H...C (MA...AC) & 2.75 & 0.0078 & 0.024 & 0.00100 & -0.80 & 3.02 & vdW \\
\hline & 4 & H...C (MA...AC) & 2.85 & 0.0066 & 0.020 & 0.00083 & -0.79 & 0.53 & vdW \\
\hline & 5 & $\mathrm{O} \ldots \mathrm{H}\left(\mathrm{MA} \ldots \mathrm{H}_{2} \mathrm{O}\right)$ & 1.74 & 0.0397 & 0.105 & -0.00615 & -1.19 & 0.06 & HB \\
\hline & 6 & $\mathrm{O} \ldots \mathrm{H}\left(\mathrm{H}_{2} \mathrm{O} \ldots \mathrm{AC}\right)$ & 2.50 & 0.0096 & 0.035 & 0.00119 & -0.84 & 0.25 & vdW \\
\hline & 7 & $\mathrm{O} \ldots \mathrm{H}\left(\mathrm{H}_{2} \mathrm{O} \ldots \mathrm{AC}\right)$ & 1.67 & 0.0502 & 0.103 & -0.01295 & -1.34 & 0.04 & CT \\
\hline & 8 & $\mathrm{H} \ldots \mathrm{O}\left(\mathrm{H}_{2} \mathrm{O} \ldots \mathrm{AC}\right)$ & 1.87 & 0.0281 & 0.097 & -0.00018 & -1.01 & 0.06 & HB \\
\hline & 9 & $\mathrm{O} \ldots \mathrm{H}\left(\mathrm{H}_{2} \mathrm{O} \ldots \mathrm{AC}\right)$ & 2.73 & 0.0073 & 0.025 & 0.00080 & -0.85 & 1.02 & vdW \\
\hline & 10 & $\mathrm{O} \ldots \mathrm{H}\left(\mathrm{H}_{2} \mathrm{O} \ldots \mathrm{AC}\right)$ & 2.24 & 0.0135 & 0.053 & 0.00176 & -0.85 & 0.10 & weak $\mathrm{HB}$ \\
\hline & 11 & $\mathrm{O} \ldots \mathrm{H}\left(\mathrm{H}_{2} \mathrm{O} \ldots \mathrm{AC}\right)$ & 2.73 & 0.0054 & 0.019 & 0.00078 & -0.80 & 0.17 & vdW \\
\hline & 12 & $\mathrm{O} \ldots \mathrm{H}\left(\mathrm{H}_{2} \mathrm{O} \ldots \mathrm{H}_{2} \mathrm{O}\right)$ & 1.86 & 0.0298 & 0.097 & -0.00094 & -1.04 & 0.04 & HB \\
\hline
\end{tabular}

\footnotetext{
${ }^{\mathrm{a}}$ The atoms belong to the corresponding specie inside parenthesis
}

${ }^{\mathrm{b}}$ Interaction types: vdW: van der Waals dispersive interaction; HB: hydrogen bond; CT: charge transfer interaction.

Table 2 illustrates the types of interactions presented in the systems MA/AC-SGs and MA/AC$\mathrm{SGs} /\left(\mathrm{H}_{2} \mathrm{O}\right)_{3}$. The corresponding structures are shown in Figures 6 and 7. Interactions for the minima of systems MA/AC-SGs/ $\mathrm{H}_{2} \mathrm{O}$ and MA/AC-SGs $/\left(\mathrm{H}_{2} \mathrm{O}\right)_{2}$ are shown in Figures $\mathbf{S 4}$ and $\mathbf{S 5}$. QTAIM results confirm that van der Waals interactions of dispersive character are the main interactions between the MA and $\mathrm{AC}$ surface, when considering the interactions between MA and the $\pi$-cloud of the AC (Figure 6 and 7). High values of the ellipticity of the electron density $(\varepsilon)$ for MA $\cdots \pi$-cloud interactions are characteristic of directionless or weak dispersive interactions and confirm that this result is in agreement with previous theoretical studies [13-15]. 
Ferino-Pérez, A.; Gamboa-Carballo; J.J., Li, Z., Campos L.C.; Jáuregui-Haza U. (2019) Explaining the interactions between metaldehyde and acidic surface groups of activated carbon under different pH conditions. J Mol Graph Model., 90:94-103.

Table 2. Typical interactions presented in the systems MA/AC-SGs and MA/AC-SGs/( $\left.\mathrm{H}_{2} \mathrm{O}\right)_{3}$

\begin{tabular}{|c|c|c|c|c|c|c|}
\hline & $\underbrace{\text { Type of interactions }}_{\text {iplexes }}$ & vdW & Weak HB & HB & CT & Total \\
\hline 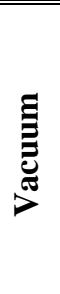 & $\begin{array}{c}\text { MA/Coronene. }{ }^{*} \\
\text { MA/AC-COO } .1^{*} \\
\text { MA/AC-OOH.1* } \\
\text { MA/AC-O-. }{ }^{*} \\
\text { MA/AC-OH.1* }\end{array}$ & $\begin{array}{l}6(100.00 \%) \\
2(40.00 \%) \\
2(50.00 \%) \\
1(33.33 \%) \\
4(80.00 \%)\end{array}$ & $\begin{array}{c}------ \\
3(60.00 \%) \\
1(25.00 \%) \\
1(33.33 \%) \\
------\end{array}$ & $\begin{array}{c}------ \\
----- \\
1(25.00 \%) \\
1(33.33 \%) \\
1(20.00 \%)\end{array}$ & $\begin{array}{l}------ \\
------ \\
------ \\
------ \\
------\end{array}$ & $\begin{array}{l}6 \\
5 \\
4 \\
3 \\
5\end{array}$ \\
\hline 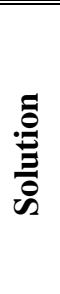 & $\begin{array}{c}\text { MA/Coronene } /\left(\mathrm{H}_{2} \mathrm{O}\right)_{3.1} 1^{*} \\
\text { MA/AC-COO } /\left(\mathrm{H}_{2} \mathrm{O}\right)_{3.1}{ }^{*} \\
\text { MA/AC-COOH} /\left(\mathrm{H}_{2} \mathrm{O}\right)_{3.1}{ }^{*} \\
\text { MA/AC-O } /\left(\mathrm{H}_{2} \mathrm{O}\right)_{3.1} \\
\left.\text { MA/AC-OH/( } / \mathrm{H}_{2} \mathrm{O}\right)_{3.1} *\end{array}$ & $\begin{array}{c}11(64.71 \%) \\
8(57.14 \%) \\
10(66.67 \%) \\
9(60.00 \%) \\
7(58.33 \%)\end{array}$ & $\begin{array}{c}1(5.88 \%) \\
---- \\
4(26.67 \%) \\
1(6.67 \%) \\
1(8.33 \%)\end{array}$ & $\begin{array}{c}5(29.41 \%) \\
6(42.86 \%) \\
----- \\
4(26.67 \%) \\
3(25.00 \%)\end{array}$ & $\begin{array}{c}------- \\
----- \\
1(6.66 \%) \\
1(6.66 \%) \\
1(8.34 \%)\end{array}$ & $\begin{array}{l}17 \\
14 \\
15 \\
15 \\
15\end{array}$ \\
\hline
\end{tabular}

Additionally, it is worth mentioning that several non-covalent interactions of greater strength as in the case of closed shell hydrogen bonds were found in almost all the complexes, especially when increasing the number of water molecules, this should enhance the adsorption process in aqueous solution. Furthermore, it can be seen in Table 2 that at least one charge transfer interaction or a strong H-bond with a certain covalency character [47] had been detected for all the complexes where a water molecule acts as an intermediary between the activated carbon surface group and the oxygen atoms of metaldehyde (Figure 7).

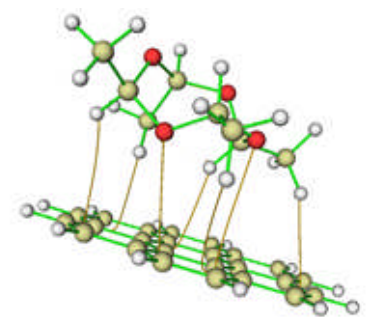

MA/Coronene. $1^{*}$

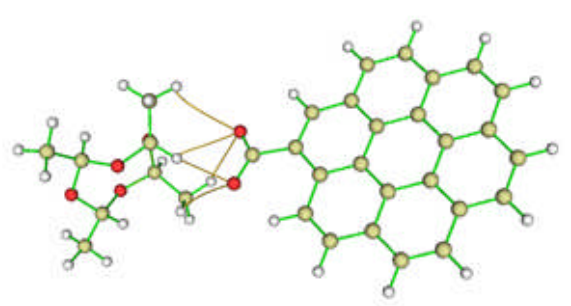

$\mathrm{MA} / \mathrm{AC}^{-\mathrm{COO}^{-} .1^{*}}$

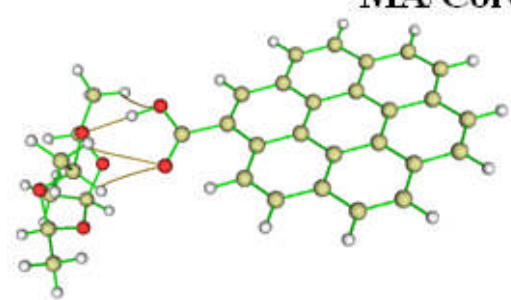

MA/AC-COOH.1*

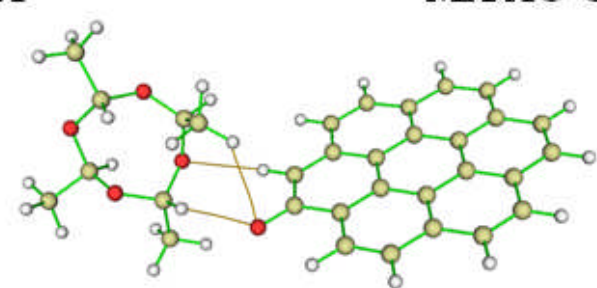

$\mathrm{MA} / \mathrm{AC}^{-} \mathrm{O}^{-} .1^{*}$

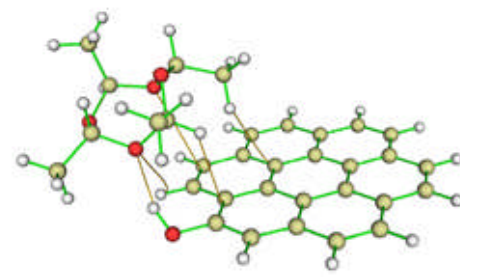

MA/AC-OH.1*

Figure 6. Interactions and bond paths obtained from QTAIM for distinctive minima structures for the systems MA/AC with and without acidic SGs 
Ferino-Pérez, A.; Gamboa-Carballo; J.J., Li, Z., Campos L.C.; Jáuregui-Haza U. (2019) Explaining the interactions between metaldehyde and acidic surface groups of activated carbon under different pH conditions. J Mol Graph Model., 90:94-103.

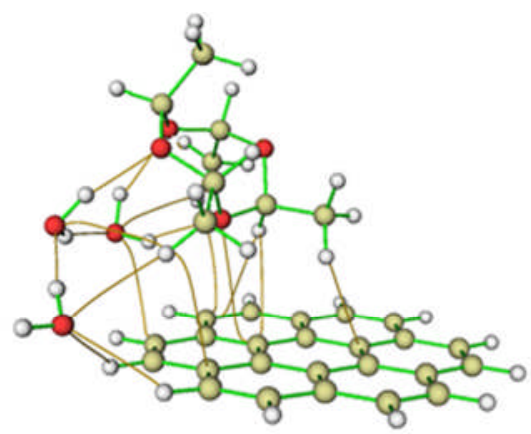

$\mathrm{MA} /$ Coronene $/\left(\mathrm{H}_{2} \mathrm{O}\right)_{3} .1^{*}$

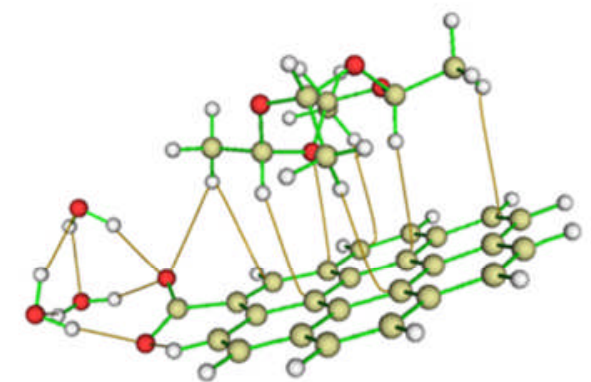

$\mathrm{MA} / \mathrm{AC}-\mathrm{COO}^{-} /\left(\mathrm{H}_{2} \mathrm{O}\right)_{3} .1^{*}$

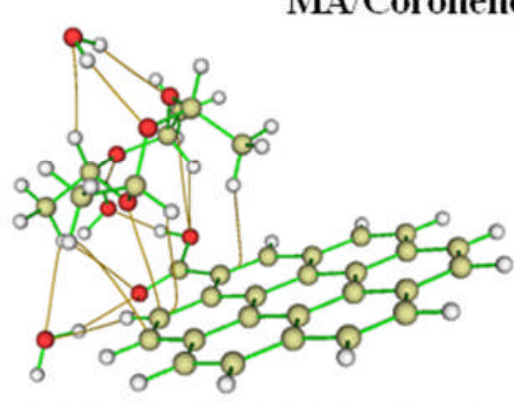

$\mathrm{MA} / \mathrm{AC}-\mathrm{COOH} /\left(\mathrm{H}_{2} \mathrm{O}\right)_{3} .1^{*}$

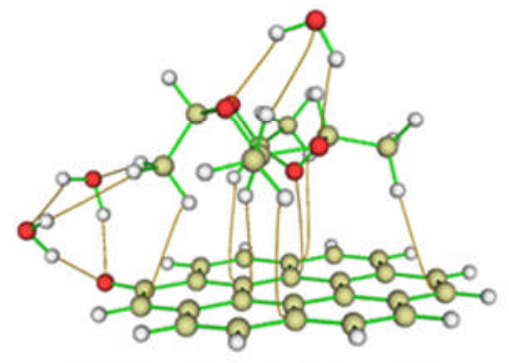

$\mathrm{MA} / \mathrm{AC}-\mathrm{O}^{-} /\left(\mathrm{H}_{2} \mathrm{O}\right)_{3} \cdot 1^{*}$

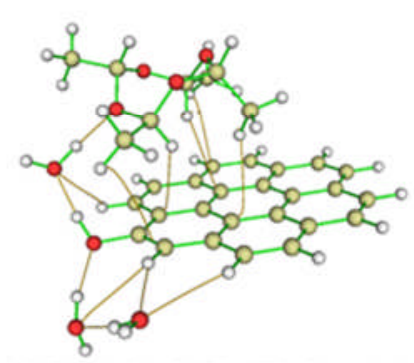

$\mathrm{MA} / \mathrm{AC}-\mathrm{OH} /\left(\mathrm{H}_{2} \mathrm{O}\right)_{3} .1^{*}$

Figure 7. Interactions and bond paths obtained from QTAIM for distinctive minima structures for the systems MA/AC/ $\left(\mathrm{H}_{2} \mathrm{O}\right)_{3}$ with and without acidic SGs

Summarizing and taking into account the results published by Salvestrini et al. [43] and this study, Figure 8 shows the relationship between theoretical and experimental results, specifically the variation of MA equilibrium concentration during adsorption of the pesticide on GAC. Over the initial range of the curve $(\mathrm{pH}<4)$ the adsorption of the MA is low; this indicates very little dependence of the adsorption process of MA with the SGs composition at low $\mathrm{pH}$ conditions, where the studied SGs remain mostly in the neutral protonated form. On the other hand, over the remaining range of the curve $(\mathrm{pH}>4) \mathrm{MA}$ equilibrium concentration decreases and reaches a minimum, this corresponds to a maximum adsorption capacity at a $\mathrm{pH}$ value of around 8 . This behavior agrees with the fact that at a $\mathrm{pH}>5$ a rough estimation gives deprotonation of $\mathrm{OH}$ surface groups lower than $3 \%$, while only $\mathrm{COOH}$ groups are deprotonated to a greater extent $(\approx$ 90\%) [50]. The - $\mathrm{COO}^{-}$is the only charged surface group, and it is predicted that carboxylic surface groups will be the main contributors to enhance MA adsorption onto AC at slightly acidic and neutral $\mathrm{pH}$ condition. 
Ferino-Pérez, A.; Gamboa-Carballo; J.J., Li, Z., Campos L.C.; Jáuregui-Haza U. (2019) Explaining the interactions between metaldehyde and acidic surface groups of activated carbon under different pH conditions. J Mol Graph Model., 90:94-103.

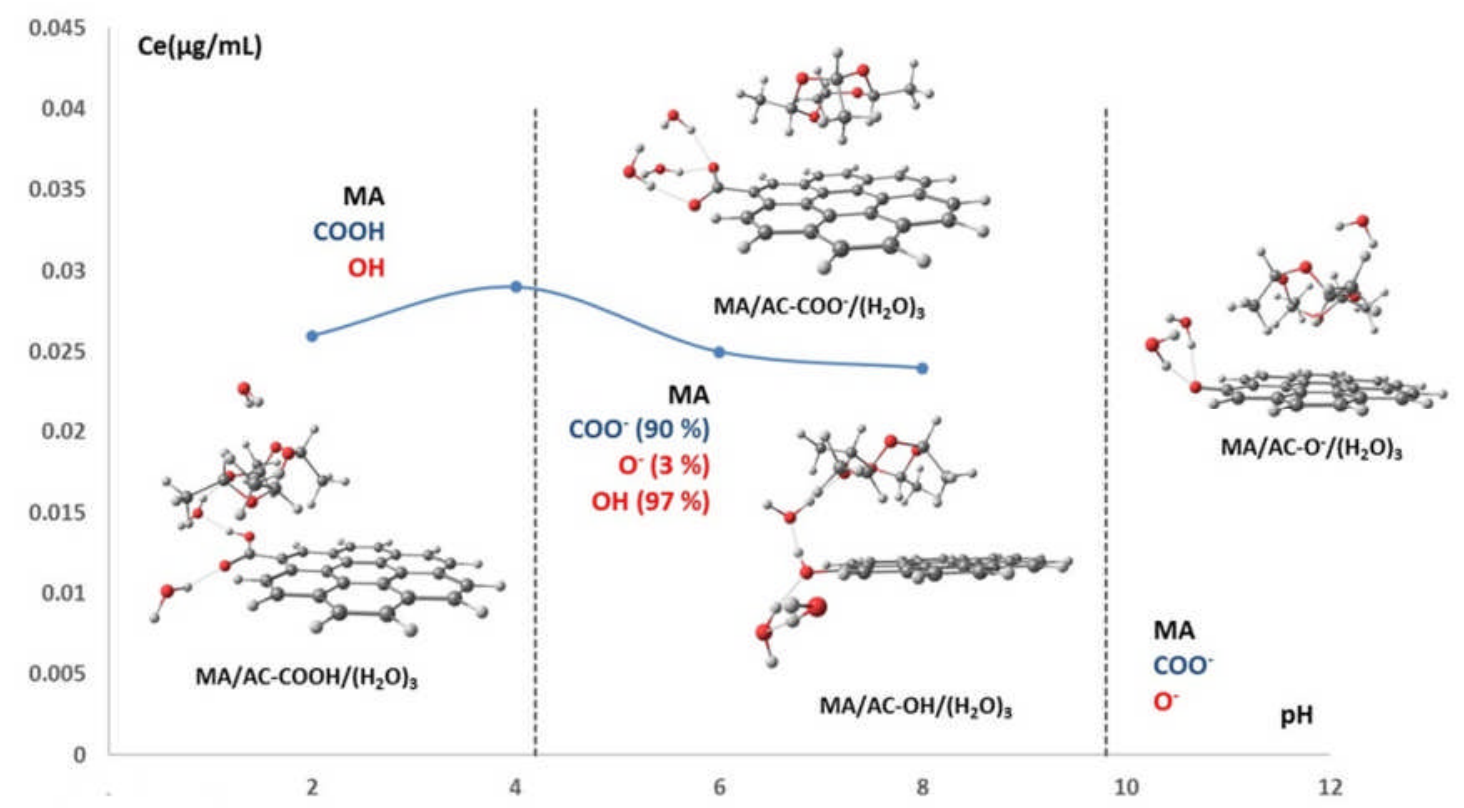

Figure 8. The relationship between experimental [10] and the theoretical results of this work.

Therefore, taking into account the theoretical results obtained in this work, the interaction of MA with the acidic surface groups is favored through dispersive and electrostatic interactions mediated by water molecules. The dispersive interactions are governed by van der Waals interactions of MA with the $\pi$-cloud of the graphitic surface of $\mathrm{AC}$, and electrostatic interactions by H-bonding interactions of MA with water, and then by H-bonding interactions of water with the SGs on AC. To summarize, it can be suggested that the mechanism of adsorption of MA occurs through physisorption. Considering the present theoretical results and the agreement between theoretical and experimental results [10], it is possible to provide insights to improve the selection process of the best-suited ACs according to the composition of the SGs, for the removal of MA from the water.

\section{Conclusions}

MMH methodology confirms that the adsorption process of metaldehyde onto activated carbon is enhanced by the introduction of acidic surface groups. The strength of the interaction between the acidic surface group and $\mathrm{MA}$ is $\mathrm{COO}^{-}>\mathrm{O}^{-}>\mathrm{COOH}>\mathrm{OH}$. The optimum conditions for this process are at neutral and basic $\mathrm{pH}$ values, where the acidic superficial groups are charged $\left(\mathrm{COO}^{-}\right.$ and $\mathrm{O}^{-}$), which is in agreement with experimental results by Busquets (2014) and Salvestrini (2017). Re-optimization using DFT M06-2X shows that in general PM7 correctly describes the geometries of the studied systems. QTAIM results confirm that present interactions have a noncovalent character, predominating dispersive interactions with the $\pi$-cloud of the AC. The water molecules tend to act as intermediaries forming a system of $\mathrm{H}$-bonds mediating the interaction between MA and the surface group. In some cases, a process of charge transfer with a certain covalent character has been observed. All these results suggest that physisorption is the main mechanism of adsorption of MA on AC in aqueous media. 
Ferino-Pérez, A.; Gamboa-Carballo; J.J., Li, Z., Campos L.C.; Jáuregui-Haza U. (2019) Explaining the interactions between metaldehyde and acidic surface groups of activated carbon under different pH conditions. J Mol Graph Model., 90:94-103.

Acknowledgments: The authors thank the UCL's Global Engagement Office for funding the research collaboration between the UCL-Department of Civil, Environmental and Geomatic Engineering and the Instituto Superior de Tecnologías y Ciencias Aplicadas (InSTEC), Universidad de La Habana. Also, ASCAT foundation and Dr. Miriam Palacios are gratefully acknowledge for connecting British and Cuban universities. Computational calculations have been performed using Wahoo, the cluster of the Centre Commun de Calcul Intensif of the Université des Antilles, Guadeloupe, France.

\section{References}

[1] Castle, G.D., Mills, G.A., Gravell, A., Jones, L., Townsend, I., Cameron, D.G., et al. Review of the molluscicide metaldehyde in the environment. Environ. Sci.: Water Res. Technol. 2017, 3, 415-28.

[2] Luo, Y., Guo, W., Ngo, H.H., Nghiem, L.D., Hai, F.I., Zhang, J., et al. A review on the occurrence of micropollutants in the aquatic environment and their fate and removal during wastewater treatment. Sci. Total Environ. 2014, 473-474, 619-41.

[3] The determination of metaldehyde in waters using chromatography with mass spectrometric detection. Agency, E. Ed., 2009.

[4] Briefing paper on metaldehyde. Water UK, 2013.

[5] Mohammadi, N., Khani, H., Gupta, V.K., Amereh, E., Agarwal, S. Adsorption process of methyl orange dye onto mesoporous carbon material-kinetic and thermodynamic studies. J. Colloid Interface Sci. 2011, 362, 457-62.

[6] Robati, D., Mirza, B., Rajabi, M., Moradi, O., Tyagi, I., Agarwal, S., et al. Removal of hazardous dyes-BR 12 and methyl orange using graphene oxide as an adsorbent from aqueous phase. Chem. Eng. J. (Lausanne). 2016, 284, 687-97.

[7] Gupta, V.K., Nayak, A., Agarwal, S., Tyagi, I. Potential of activated carbon from waste rubber tire for the adsorption of phenolics: Effect of pre-treatment conditions. J. Colloid Interface Sci. 2014, 417, 420-30.

[8] Zhou, Y., Liu, X., Tang, L., Zhang, F., Zeng, G., Peng, X., et al. Insight into highly efficient co-removal of p-nitrophenol and lead by nitrogen-functionalized magnetic ordered mesoporous carbon: Performance and modelling. J. Hazard. Mater. 2017, 333, 80-7.

[9] Durimel, A., Altenor, S., Miranda-Quintana, R.A., Couespel Du Mesnil, P., Jauregui-Haza, U., Gadiou, R., et al. pH dependence of chlordecone adsorption on activated carbons and role of adsorbent physico-chemical properties. Chem. Eng. J. (Lausanne). 2013, 229, 239-349.

[10] Salvestrini, S., Vanore, P., Bogush, A., Mayadevi, S., Campos, L.C. Sorption of metaldehyde using granular activated carbon. Journal of Water Reuse and Desalination. 2017, 280-7.

[11] Gupta, V.K., Saleh, T.A. Sorption of pollutants by porous carbon, carbon nanotubes and fullerene- An overview. Environ. Sci. Pollut. Res. 2013, 20, 2828-43.

[12] Pradhan, B.K., Sandle, N. Effect of different oxidizing agent treatments on the surface properties of activated carbons. Carbon. 1999, 37, 1323-32.

[13] Qin, W., Li, X., Bian, W.-W., Fan, X.-J., Qi, J.-Y. Density functional theory calculations and molecular dynamics simulations of the adsorption of biomolecules on graphene surfaces. Biomaterials. 2010, 31, 1007-16.

[14] Liu, J., Cheney, M.A., Wu, F., Li, M. Effects of chemical functional groups on elemental mercury adsorption on carbonaceous surfaces. J. Hazard. Mater. 2011, 186, 108-13.

[15] Sun, Y., Yang, S., Chen, Y., Ding, C., Cheng, W., Wang, X. Adsorption and desorption of U(VI) on functionalized graphene oxides: A combined experimental and theoretical study. Environ. Sci. Technol. 2015. 
Ferino-Pérez, A.; Gamboa-Carballo; J.J., Li, Z., Campos L.C.; Jáuregui-Haza U. (2019) Explaining the interactions between metaldehyde and acidic surface groups of activated carbon under different pH conditions. J Mol Graph Model., 90:94-103.

[16] de Ridder, D.J., McConville, M. Development of a predictive model to determine micropollutant removal using granular activated carbon. Drinking Water Engineering Science. 2009, 2, 57-62.

[17] Terzyk, A.P., Gauden, P.A., Zielinski, W., Furmaniak, S., Wesołowski, R.P., Klimek, K.K. First molecular dynamics simulation insight into the mechanism of organics adsorption from aqueous solutions on microporous carbons. Chem. Phys. Lett. 2011, 515, 102-8.

[18] Furmaniak, S., Terzyk, A.P., Gauden, P.A., Kowalczyk, P., Szymański, G.S. Influence of activated carbon surface oxygen functionalities on $\mathrm{SO} 2$ physisorption-simulation and experiment. Chem. Phys. Lett. 2013, 578, 85-91.

[19] Durimel, A., Passé-Coutrin, N., Jean-Marius, C., Gadiou, R., Enríquez-Victorero, C., Hernández-Valdés, D., et al. Role of acidic sites in beta-hexachlorocyclohexane $(\beta-\mathrm{HCH})$ adsorption by activated carbons: molecular modelling and adsorption-desorption studies. RSC Adv. 2015, 5, 85153-64.

[20] Enriquez-Victorero, C., Hernández-Valdés, D., Montero-Alejo, A.L., Durimel, A., Gaspard, S., Jáuregui-Haza, U. Theoretical study of $\gamma$-hexachlorocyclohexane and $\beta$ hexachlorocyclohexane isomers interaction with surface groups of activated carbon model. J. Mol. Graphics Model. 2014, 51, 137-48.

[21] Hernández-Valdés, D., Enriquez-Victorero, C., Pizarro-Lou, L., Turiño-Pérez, D., DucatPagés, L., Arias, M., et al. Interaction of paracetamol and ${ }^{125} \mathrm{I}$-paracetamol with surface groups of activated carbon: theoretical and experimental study. J. Radioanal. Nucl. Chem. 2015, 305, 60922.

[22] Gamboa-Carballo, J.J., Melchor-Rodríguez, K., Hernández-Valdés, D., Enriquez-Victorero, C., Montero-Alejo, A.L., Gaspard, S., et al. Theoretical study of chlordecone and surface groups interaction in an activated carbon model under acidic and neutral conditions. J. Mol. Graphics Model. 2016, 65, 83-93.

[23] Melchor-Rodríguez, K., Gamboa-Carballo, J.J., Ferino-Pérez, A., Passe-Coutrin, N., Gaspard, S., Jáuregui-Haza, U.J. Theoretical study on the interactions between chlordecone hydrate and acidic surface groups of activated carbon under basic $\mathrm{pH}$ conditions. J. Mol. Graphics Model. 2018.

[24] Montero-Cabrera, L.A., Esteva, A.M., Molina, J., Zapardiel, A., Hernández, L., Márquez, $\mathrm{H}$., et al. A theoretical approach to analytical properties of 2,4-diamino-5-phenylthiazole in water solution. Tautomerism and dependence on pH. J. Am. Chem. Soc. 1998, 120, 12023-33.

[25] Montero-Cabrera, L.A., Llano, J., Molina, J., Fabian, J. Multiple minima hypersurfaces of water clusters for calculations of association energy. Int. J. Quantum Chem. 2000, 79, 8-16.

[26] Hohenberg, P., Kohn, W. Inhomogeneous electron gas. Phys. Rev. 1964, 136, B864-B71.

[27] Kohn, W., Sham, L.J. Self-consistent equations including exchange and correlation effects. Phys. Rev. 1965, 140, A1133-A8.

[28] Bader, R.F.W. The density in density functional theory. J. Mol. Struct. 2010, 943, 2-18.

[29] Bader, R.F.W. A quantum theory of molecular structure and its applications. Chem. Rev. 1991, 91, 893-298.

[30] Cabaleiro-Lago, E.M., Rodríguez-Otero, J., Peña-Gallego, Á. Computational study on the characteristics of the interaction in naphthalene $\cdots\left(\mathrm{H}_{2} \mathrm{X}\right) \mathrm{n}=1,2(\mathrm{X}=\mathrm{O}, \mathrm{S})$ clusters. J. Phys. Chem. A. 2008, 112, 6344-50.

[31] Zhao, Y., Truhlar, D.G. A prototype for graphene material simulation: structures and interaction potentials of coronene dimers. J. Phys. Chem. 2008, 112, 4061-7.

[32] Jenness, G.R., Jordan, K.D. DF-DFT-SAPT Investigation of the Interaction of a water molecule to coronene and dodecabenzocoronene: Implications for the water graphite interaction. J. Phys. Chem. 2009, 123, 10242-8.

[33] Ishimoto, T., Koyama, M. Theoretical study on interaction energy between water and graphene model compound. J. Comput. Chem., Jpn. 2014, 13, 171-2. 
Ferino-Pérez, A.; Gamboa-Carballo; J.J., Li, Z., Campos L.C.; Jáuregui-Haza U. (2019) Explaining the interactions between metaldehyde and acidic surface groups of activated carbon under different pH conditions. J Mol Graph Model., 90:94-103.

[34] Durimel, A., Passé-Coutrin, N., Jean-Marius, C., Gadiou, R., Enriquez-Victorero, C., Hernández-Valdés, D., et al. Role of acidic sites in beta-hexachlorocyclohexane (b-HCH) adsorption by activated carbons: molecular modelling and adsorption-desorption studies. RSC Adv. 2015, 5, 85153-64.

[35] Lerf, A., He, H., Forster, M., Klinowski, J. Structure of graphite oxide revisited. J. Phys. Chem. B. 1998, 102, 4477-82.

[36] Codorniu-Hernández, E., Mesa-Ibirico, A., Montero-Cabrera, L.A., Martínez-Luzardo, F., Borrmann, T., Stohrer, W.-D. Theoretical study of flavonoids and proline interactions. Aqueous and gas phases. J. Mol. Struct.: THEOCHEM. 2003, 623, 63-73.

[37] Codorniu-Hernández, E., Mesa-Ibirico, A., Hernández-Santiesteban, R., Montero-Cabrera, L.A., Martínez-Luzardo, F., Santana-Romero, J.L., et al. Essential amino acids interacting with flavonoids: A theoretical approach. Int. J. Quantum Chem. 2005, 103, 82-104.

[38] Codorniu-Hernández, E., Boese, A.D., Schauerte, C., Rolo-Naranjo, A., Miranda-Quintana, R., Montero-Cabrera, L.A., et al. MMH-2 as a new approach for the prediction of intermolecular interactions: the crystal packing of acetamide. CrystEngComm. 2009, 11, 2358-70.

[39] Hernández Valdés, D., Enríquez Victorero, C., Jáuregui Haza, U., Hernández Valdés, P., Gonzáles Santana, S. Granada modificado con restricción geométrica. Revista Cubana de Ciencias Informáticas. 2013, 7, 9-15.

[40] Montero-Cabrera, L.A. Manual del usuario GRANADA. 2000.

[41] Stewart, J.J.P. Optimization of parameters for semiempirical methods VI: more modifications to the NDDO approximations and re-optimization of parameters. Journal of Molecular Modeling. 2013, 19, 1-32.

[42] Stewart, J.J.P. MOPAC2016. Stewart Computational Chemistry, Colorado Springs, CO, USA, 2016.

[43] Hostaš, J., Řezáč, J., Hobza, P. On the performance of the semiempirical quantum mechanical PM6 and PM7 methods for noncovalent interactions. Chem. Phys. Lett. 2013, 568, 161-6.

[44] Frisch, M.J., Trucks, G.W., Schlegel, H.B., Scuseria, G.E., Robb, M.A., Cheeseman, J.R., et al. Gaussian 09, Revision A. 01. Gaussian, Inc., Wallingford CT, 2009.

[45] Johnson, E.R., Mackie, I.D., DiLabio, G.A. Dispersion interactions in density-functional theory. J. Phys. Org. Chem. 2009, 22, 1127-35.

[46] Nakanishi, W., Hayashi, S., Narahara, K. Atoms-in-molecules dual parameter analysis of weak to strong interactions: behaviors of electronic energy densities versus laplacian of electron densities at bond critical points. J. Phys. Chem. A. 2008, 112, 13593-9.

[47] Nakanishi, W., Hayashi, S., Narahara, K. Polar coordinate representation of $\mathrm{H}_{\mathrm{b}}\left(\rho_{\mathrm{c}}\right)$ versus $\left(\hbar^{2} / 8 \mathrm{~m}\right) \nabla^{2} \rho_{\mathrm{b}}\left(\mathrm{r}_{\mathrm{c}}\right)$ at BCP in AIM analysis: classification and evaluation of weak to strong interactions. J. Phys. Chem. 2009, 113, 10050-7.

[48] Lu, T., Chen, F. Multiwfn: a multifunctional wavefunction analyzer. J. Comput. Chem. 2012, 33, 580-92.

[49] Busquets, R., Kozynchenko, O.P., Whitby, R.L., Tennison, S.R., Cundy, A.B. Phenolic carbon tailored for the removal of polar organic contaminants from water: A solution to the metaldehyde problem? Water Res. 2014, 61, 46-56.

[50] Picaud, S., Collignon, B., Hoang, P.N., Rayez, J.-C. Adsorption of water molecules on partially oxidized graphite surfaces: a molecular dynamics study of the competition between $\mathrm{OH}$ and COOH sites. Phys. Chem. Chem. Phys. 2008, 10, 6998-7009. 